\title{
11 Indigenous Data Sovereignty and the role of universities
}

\author{
Tennille L. Marley
}

\section{Introduction}

American Indians and Alaska Natives (AIAN) and Indigenous Peoples (IP) throughout the world have long been subject to unethical research practices and abuse that continue today. In the United States, phrenology was practiced to establish White superiority and justify ongoing genocide (Thorton, 1987). In the 1860s, under the direction of the US Surgeon General, soldiers and army personnel were ordered to collect human remains and objects from battle sites, hospitals and burial grounds for research purposes. Not until 1990, with the Native American Graves Protection and Repatriation Act (NAGPRA) were AIAN Nations able to reestablish ownership and repatriate items, objects and human remains (Trope \& Echo-Hawk, 1992). More recently, the Havasupai Nation settled with Arizona State University and the Arizona Board of Regents for improper research use of blood samples collected as part of a diabetes project. The issues associated with the Havasupai case included risks of harm, cultural harm, informed consent, stigmatization, identification, and control and ownership of data (Harmon, 2010).

Indigenous culture, intellectual property and knowledge continue to be abused, stolen, appropriated and exploited for various uses. Names and objects are used commercially and as sports mascots, such as the Cleveland Indians and Jeep Cherokee. So too do we see the appropriation of Indigenous data in the fashion world, such as headdresses and Indigenous-inspired textiles. In addition, data generated from research with and information about Indigenous Peoples are also at risk due to their availability online and in archives. These data and information that are used irresponsibly can threaten the cultural and political sovereignty of AIAN and other IP. Data that are stored in US government archives are especially at risk since they are part of the public domain and are available to the public for research and other purposes. For example, in 2015, Peter Nabokov, an anthropologist and professor at the University of California Los Angeles, edited and published Origin Myths of the Acoma Pueblo that included creation and migration songs and stories. Nabokov's book is a republication of an 1842 US government archived document (Hunt \& Nabokov, 2015). The Acoma Nation have the sovereign right to own the contents of the book as intellectual property, the collective cultural expressions and traditional knowledge, but since the original book was 
held in government archives for over 75 years, it is considered part of the public domain and cannot be returned to them (Hurley, Kostelecky, \& Aguilar, 2017).

Largely in response to previous and ongoing research abuses, many AIAN and other IP are now asserting their right to govern research in their communities. However, much research in Indigenous communities continues to be conducted by or with researchers at academic institutions. University institutional review boards (IRB) must increasingly contend with AIAN and IP asserting their rights to data. In this chapter, I discuss AIAN political and cultural sovereignty, Indigenous Data Sovereignty (IDS), AIAN research mechanisms, university IRBs and end with a discussion of what universities and researchers can do to respect AIAN and IP interests. As more IP assert data sovereignty, universities will have to grapple with Native Nations in order to conduct research in their communities.

\section{Political sovereignty}

In the United States, federally recognized AIAN nations hold a unique position as sovereign entities with a government-to-government relationship with the federal government. Recognition of this sovereignty can be traced back to the 1700s when European nations, and later the United States, entered into treaties with Tribal Nations (Wilkins \& Stark, 2017). Because of this acknowledgment of their sovereignty, federally recognized American Indian Nations and Alaska Native corporations hold political statuses that are different than other racial/ethnic groups in the United States. In addition to being part of a racial/ethnic group, members of these federally recognized entities are also part of political group with special rights and benefits from the federal government (Wilkins \& Stark, 2017).

AIAN and IP continue to fight to protect and assert their sovereignty with respect to governance, culture, research and other areas. In the past, non-Indigenous researchers have exploited AIAN and IP for their own benefit (Brayboy \& Deyhle, 2000). As Lomawaima (2000) explains, "until quite recently ... researchers could set their own research agendas, devise their own questions, develop whatever methodology suited their agenda, and do as they pleased without having to consult with or defer to tribal polities" (p. 6). Consequently, more AIAN and IP are asserting their sovereignty with respect to research and securing rights and ownership of their knowledge, objects and cultural expressions that could be considered data by researchers.

\section{Indigenous Data Sovereignty and qualitative data}

Data ownership and data sharing are growing concerns among AIAN and other IP. No overarching legal structures exist in the United States to govern AIAN data ownership or sharing. As a result, AIAN data collected on AIAN lands are vulnerable to non-consensual use by other researchers for secondary analysis. Data sharing plans, including those governing qualitative datasets, are increasingly required by governmental and foundation research grants. The reuse of qualitative data is especially susceptible to causing harm for research participants and 
communities due to its sensitive nature (Heaton, 2004). These data can be difficult to anonymize or strip of sensitive information. In the context of secondary analysis, important indicators of meaning, such as metadata, are often missing thus making these data ripe for misinterpretation (Mills, 2017; Thomson et al., 2005). Other issues related to secondary use of qualitative data are ethical in nature, such as obtaining informed consent where future use of data is not known (Irwin, 2013).

Despite concerns regarding secondary analysis of qualitative data, interest in data sharing and archiving has increased among qualitative researchers (Elman, Kapiszewski, \& Vinuela, 2010). Consequently, we are likely to see the increasing re-use of qualitative data concerning AIAN communities, which to date has largely only been the case with quantitative data. The long history of unethical research practices by Western researchers rings a warning bell that researchers much heed (Tsosie, 2007). I now turn to the Indigenous Data Sovereignty movement as an example of a critical framework that Native Nations and Indigenous communities can draw on to protect their data. Indigenous Data Sovereignty is: "[the] right of Indigenous Peoples to govern the collection, ownership, and application of data about Indigenous communities, peoples, lands, and resources" (Rainie et al., 2019). Article 31 of the United Nations Declaration on the Rights of Indigenous Peoples (2007), adopted by the United Nations General Assembly on September 13, 2007, and finally adopted by the United States in 2010, recognizes this inherent right. It states:

Indigenous Peoples have the right to maintain, control, protect and develop their cultural heritage, traditional knowledge and traditional cultural expressions, as well as the manifestations of their sciences, technologies and cultures, including human and genetic resources, seeds, medicines, knowledge of the properties of fauna and flora, oral traditions, literatures, designs, sports and traditional games and visual and performing arts. They also have the right to maintain, control, protect and develop their intellectual property over such cultural heritage, traditional knowledge, and traditional cultural expressions.

Indigenous Data Sovereignty seeks not only to control, own and govern research and data, but also to protect sovereignty and culture that are often interlinked: "Qualitative" data, including cultural expressions, stories, interviews, oral histories, data from previous research.

\section{Cultural sovereignty}

Beyond the governance, collection and ownership of data, Indigenous Data Sovereignty also seeks to protect Indigenous cultural sovereignty. Indigenous sovereignty is threatened when cultural sovereignty is violated through exploitation, theft and misrepresentation of culture, especially through qualitative data, such as interviews held in government archives. As a result, it is important for AIAN nations to protect their cultural and political sovereignty by exercising 
Indigenous Data Sovereignty. Coffey and Tsosie (2001) call for a vision of tribal sovereignty in which cultural sovereignty is fundamental. They define cultural sovereignty as,

the effort of Indian nations and Indian people to exercise their own norms and values instructing their collective futures ... [it] is inherent in every sense of that word, and it is up to Indian people to define, assert, protect, and insist upon that right.

(Coffey \& Tsosie, 196)

Additionally, David Matheson, a Coeur d'Arlene leader, said, "[t]ribal sovereignty is more than a doctrine, it is our existence and our continued survival. ... Our culture is tied up in everything that we do" (Matheson, 2002, p. 18). Finally, W. Richard West, former director of the Museum of the American Indian states, "Political sovereignty and cultural sovereignty are linked inextricably, because the ultimate goal of political sovereignty is the protecting of a way of life" (as cited in Bordewich, 1997, pp. 171-172).

Ultimately, cultural sovereignty is essential for the survival of Indigenous Nations. Culture, including language, songs, oral histories/stories, dress, ceremonies, dances, etc., as well as land and community are at the core of Indigenous identity and way of life. As Deloria Jr (1979, p. 27) said:

Sovereignty, in the final instance, can be said to consist more of continued cultural integrity than of political powers and to the degree that a tribal nation loses its sense of cultural identity, to that degree it suffers a loss of sovereignty

\section{AIAN mechanisms for research}

One of the ways in which AIAN nations exercise sovereignty is by creating and implementing laws and policies with respect to research taking place on their lands. AIAN nations have mechanisms to regulate research including the collection and use of data, data ownership, data archiving, control of intellectual property, Indigenous knowledge and cultural expressions. Some of the mechanisms include approval by Tribal Council, committee review, permits, legal contracts, research and ethics boards and other formal written policies (Macaulay et al., 1998; Nason, 1996). For example, Hopi and Navajo research guidelines extend back more than 20 years and express

concerns about commercialization, alienation, and inappropriate dissemination of intellectual property and cultural patrimony ... [including] fair return, sharing of results, local availability of collected data in tribal archives, translation difficulties, challenges of consistency with federal agency regulations - that tribes are best suited to identify. 
Another example is with the Inter-Apache Policy on Repatriation and the Protection of Apache Cultures established in 1996 by the nine Apace Tribes. Driven by several acts including the Native American Graves Protection and Repatriation Act of 1990 and other laws promoting the preservation of items, places, customs and beliefs, the policy was created to address "the abuse, destruction, and misappropriations [including unauthorized commercial use] of Apache culture, history, sacred places and objects, cultural property, religious freedom and cultural rights" (White Mountain Apache Tribe, 1996). "Cultural property in the policy are defined as images, text, music, songs, stories, symbols, beliefs, customs, ideas, and items linked to the history and culture of the Apache tribes in any media" (White Mountain Apache Tribe, 1996). The policy also objects to the "possession, public exhibition, scientific study, destructive analysis, or other inappropriate use of Apache cultural property (except as expressly permitted by the concerned tribe or when essential to a criminal investigation)" (Nason, 1996).

In the same year, at the American Indian Higher Education Consortium Native Research and Scholarship Symposium, scholars and tribal leaders emphasized a research agenda to help maintain sovereignty and nationhood. Intellectual property rights and the appropriation and exploitation of culture and knowledge, were topics of concern and they emphasized the need for more tribal regulation, monitoring and governance of research. A recommendation from the symposium included the creation of a "Council of Elders" at the tribal level to clarify which cultural practices should be protected and to limit "exploitation of our cultures by exposing our religions, social practices, languages, and cultural knowledge" (Bull, 1997).

Today, a growing number of AIAN nations are asserting and exercising sovereignty over research taking place on their lands and with their peoples by creating their own IRBs. Broadly defined, IRBs are administrative bodies that strive to protect the rights, welfare and privacy of human research subjects and have the authority to approve, disapprove, monitor and require modifications of all research that falls under its jurisdiction (45 CFR 46). Specifically, tribal IRBs assume responsibility for ensuring that research taking place on tribal lands is ethical and they oversee the research process (US Department of Health \& Human Services, 2017). Their responsibilities include protecting the people, the nation, tribal communities and tribal resources.

The first AIAN nation IRB was the Navajo Nation Human Research Review Board (NNHRRB) established in 1996 and revised in 2002. It has the responsibility to "regulate, monitor, and control all research within the boundaries of the Navajo Nation" (Navajo Nation, 2005). The NNHRRB 12-phase process is as follows: (1) secure support via resolution with community partner; (2) secure letter of support(s) from tribal program(s) partner; (3) Human Research Review Board review of proposed research; (4) study presentation at an NNRRB meeting where study is approved, requires modification or disapproved; (5) implementation of study; (6) data analysis and presentation of findings at NNHRRB meeting; (7) work session with tribal partner and others to modify research report with unique partner interpretations; (8) submission of a comprehensive research report, 
including dissemination plan; (9) transfer of data to relevant partner; (10) submission of a complete, approved and publishable manuscript; (11) presentation of study results and implications to community and partners and (12) final data are given to the Navajo Nation Resource Center (Navajo Nation, n.d.). For research involving the collection of historic information, use of ethnographic methods to collect data, interviewed audio or video recordings, a permit must be secured by the Navajo Nation Historic Preservation Department. The department is charged with protecting, preserving and continuing Navajo cultural heritage and traditions to maintain the integrity of the Navajo Nation's traditions and cultures (Navajo Nation, 2019). The NNHRRN is just one example of an AIAN Nation exercising their political sovereignty over data and research, which falls under the definition of Indigenous Data Sovereignty (Carroll, Rodriguez-Lonebear, \& Martinez, 2019).

The Indigenous Data Sovereignty movement is growing across the globe and the United States. An increasing number of AIAN and IP are moving toward Indigenous Data Sovereignty by enacting Indigenous data governance and other mechanisms. Indigenous data governance is determining "when, how and why our data ... are gathered, analyzed, accessed and used; and ensure that Indigenous data reflects ... [Indigenous] priorities, values, culture, lifeworlds and diversity" (Walter, 2018). The ways in which tribes are exercising Indigenous Data Sovereignty are by "developing principles of Indigenous Data Governance, research protocols, research review boards, data sharing agreements, and data repositories" (Carroll et al., 2019, p. 14).

\section{University guidelines}

Native Nations have long been subject to unethical research by researchers from academic institutions. One of the more recent and well-known research abuses occurred on the Havasupai Indian Reservation, located in Arizona. It is often referred to as the "Havasupai Blood Case". In 1990, as part of a study on diabetes, blood samples were taken from over 200 tribal members to identify genetic links with diabetes. The samples were widely shared and used to conduct studies of schizophrenia, inbreeding, evolution and migration that contradicted their stories and beliefs. In 2003, the Havasupai discovered that their blood samples were used outside the scope of what they believed they consented to and demanded the return of the samples. After six years of fighting, they settled with Arizona State University and the Arizona Board of Regents and as part of the settlement, the remaining samples were finally returned to them. Numerous research articles and dissertations were published using the samples and they were never recanted. This case is a demonstration of unethical research practices condoned by a university that has caused great harm to Indigenous Peoples (Harmon, 2010).

University IRBs are tasked with the responsibility of protecting the rights and welfare of human subjects involved in research as required by the "Common Rule" (45 CFR 56). The IRB reviews the proposed research and has the authority 
to approve, require modifications for approval and disapprove research according to the Common Rule. The foundation of the Common Rule is the Belmont Report that identifies basic ethical principles for biomedical and behavioral research with human subjects (National Commission for the Protection of Human Subjects of Biomedical and Behavioral Research, 1979). The principles of the Common Rule are respect for persons, beneficence and justice (US Department of Health \& Human Services, n.d.). Respect for persons is practiced through informed consent; individuals are given the opportunity to choose to participate in a study or not. Potential participants are given information about the study, insuring that they understand the study and how it may affect them, and are informed that their participation is voluntary. Beneficence includes the assessment of risks and benefits; studies should be designed to maximize benefits while minimizing risks. And justice entails the selection of subjects, that procedures for the selection of subjects are fair and not exploitive (US Department of Health \& Human Services, n.d.).

Given the history of research abuses Native Nations have undergone and the assertion of their sovereignty over research taking place on their lands, researchers and university IRBs have an obligation to understand research requirements (IRBs or other mechanisms) of Native Nations and how to manage the conditions and interests of their institutional IRBs and those of Native Nations. A growing number of universities are creating policies, procedures and guidelines to address tribal concerns, interests and requirements regarding research with Native Nations. Some, but not all, existing guidelines acknowledge tribal sovereignty, including following tribal laws and procedures for research. Some also recognize that the Common Rule does not provide adequate protections so additional IRB requirements are necessary. I provide three examples from the Oregon State University (OSU), the University of New Mexico (UNM) and the University of Montana (UM).

Oregon State University provides guidelines to help researchers conducting research with Native Nations. The guidelines state that in addition to the OSU IRB, proposed research may have to undergo additional reviews by Native Nations or tribally designated entities. In those cases, a letter of support or tribal resolution must be submitted to the OSU IRB as part of the review. After OSU IRB approval, the study documents can be sent out to other review boards if necessary. The guidelines also suggest researchers consider the following: (1) access to phone, email and/or transportation; (2) required resources from the tribe such as meeting space; (3) manuscript review prior to publication and (4) data ownership since OSU has a policy that requires study-related documents to be stored by the principal investigator in an accessible OSU-audit location for three years after the study ends (Oregon State University, 2016).

The UNM also provides guidelines for researchers with IP that acknowledges Native Nation sovereignty and the need for requirements beyond federal and university policies. The key principle is societal benefit wherein study results should be beneficial to the tribe and findings should be useful and accessible by providing information that offers potential solutions, including improved community 
well-being or positive policy impact. The policy encourages developing relationships with Native Nations that are sincere, enduring and based on trust to ensure that research is relevant and appropriate. Gaining permission and letters of support for a study is dependent on Native Nation procedures, whether it is a tribe or an outside entity. Some Native Nation procedures depend on obtaining university IRB approval prior to their review. Where that is the case, the researcher will have to amend their IRB according to tribal stipulations after the tribe approves their study. In terms of data ownership, the policy recognizes the right of Native Nations to own and control data collected in their communities, and researchers must comply (University of New Mexico, n.d.).

In addition, UM also provides comprehensive guidelines titled, "Collaborating with Indigenous People". The guidelines acknowledge tribal sovereignty and the rights of Native Nations to establish their own rules, policies and procedures for research on their lands. It also recognizes the rights tribes have over shared information such as cultural knowledge and traditions. Further, it details the right to stop research, control how any information will be used and that the information collected may become property of the Native Nation. In terms of approvals and agreements, Native Nations have the right to enter into agreements where the tribe assumes IRB. In addition, at a minimum, a project director or principal investigator shall work with and comply with IP requirements including collaboration, ownership and protection of information, and permission to disseminate research findings. The guidelines also state that a memorandum of understandings may be necessary in addition to UM or tribal IRB review. Some of the components may include collaboration, how the research will benefit the community, and ownership of data, as just a few examples.

Finally, the UM policy provides guiding principles for researchers with descriptions and vignettes. The principles include (1) Native centered; (2) respect; (3) self-reflection and cultural humility; (4) authentic relationships; (5) honor community time frames; (6) build on strengths; (7) co-learning and ownership; (8) continual dialog; (9) transparency and accountability; (10) integrity and (11) community relevance (University of Montana, n.d.).

The university IRB examples above demonstrate the varying degrees to which university research guidelines affirm Indigenous political, cultural and data sovereignty. While the OSU guidelines fall short in supporting Native Nation sovereignty, UNM and UM provide much more support with regard to cultural, political and data sovereignty. Although the OSU IRB require Native Nation approval as part of the research review process, it stipulates that the principal investigator, and not the tribe, store the data and study materials. The UNM and UM policies emphasize the obligation of the principal investigator to follow rules, regulations, policies and procedures of Native Nations. They acknowledge that Native Nations have their own rules, policies and procedures for research that include ownership, materials, information, samples and review for outside dissemination, sensitivity to traditions, knowledge and culture, that researchers must follow. Both the UNM and UM guidelines support the right to limit or restrict various types of information. Finally, the UNM and UM explicitly emphasize community benefit and collaboration. The UM 
and UNM demonstrate that university IRBs can support, respect and acknowledge tribal culture, political and data sovereignty.

\section{Discussion and conclusion}

American Indians, Alaska Natives and other IP have the inherent rights to govern research on their lands and through mechanisms of their choosing. In instances where there are limited or no research mechanisms in place, universities have an obligation to adopt guidelines that are respectful and mindful of tribal political, cultural and data sovereignty. Despite some procedures in place, issues exist that are not addressed and are outside the control of both tribal and university IRBs, namely archived, shared and open data. The use of these data (Indigenous intellectual property, knowledge, songs, oral histories/stories, ceremonies, dances, texts, images, names and objects) are especially at risk of exploitation, abuse, appropriation, theft and misrepresentation.

Universities and researchers have an obligation to acknowledge and respect tribal and cultural sovereignty, in part because of their long history of research abuses at the hand of researchers and because they can adopt and implement additional research guidelines beyond the Common Rule. University IRB guidelines can be broadened to include, at a minimum, acknowledging and respecting tribal sovereignty. They can further be expanded to adopt rules in alignment with Indigenous Data Sovereignty, including expanding respect for persons, beneficence and justice to include Indigenous communities (Research Ethics Training for Health in Indigenous Communities, University of Washington, 2018). The UM and UNM serve as models that university IRBs could adopt.

University IRBs could require additional training with respect to AIAN communities such as the Research Ethics Training for Health in Indigenous Communities (Ethics training toolkit) curriculum (University of Washington, n.d.). The AIANspecific curriculum covers the following: (1) research with AIAN communities; (2) the history of ethical regulations; (3) what is human subjects research?; (4) institutional review board (IRB); (5) risks and benefits from research; (6) ensuring confidentiality and managing risk; (7) informed consent; (8) vulnerability; (9) children in research; and (10) unanticipated problems and reporting requirements in research. (Pearson et al., 2019). There are also a number of resources available to researchers regarding research with AIAN communities such as Guiding Principles for Engaging in Research with Native American Communities that was developed at the University of New Mexico and Walk Softly, and Listen Carefully, by the National Council of American Indians Policy Research Center and Montana State University Center for Native Health Partnerships (University of New Mexico, 2012; NCAI, 2012).

The exploitation, appropriation and misrepresentation of AIAN data have to end. As the Indigenous Data Sovereignty movement grows, universities and researchers will have to face IP and Native Nation political, cultural and data and research rights. Universities and researchers need to take it upon themselves to respect those rights to help ensure the survival of AIAN as distinctive, sovereign societies. 


\section{References}

Bordewich, F.M. (1997). Killing the White Man's Indian: Reinventing Native Americans at the End of the Twentieth Century. New York, NY: Anchor Books.

Brayboy, B.M., \& Deyhle, D. (2000). Insider-outsider: researchers in American Indian communities. Theory into Practice, 39(3 SRC-GoogleScholar), 163-169.

Bull, C.C. (1997). A native conversation about research and scholarship. Tribal College, 9(1), 17.

Carroll, S.R., Rodriguez-Lonebear, D., \& Martinez, A. (2019). Indigenous data governance: strategies from united states native nations. Data Science Journal, 18(1), 31.

Coffey, W., \& Tsosie, R. (2001). Rethinking the tribal sovereignty doctrine: cultural sovereignty and the collective future of Indian nations. Stanford Law and Policy Review, 12, 191.

Deloria Jr, V. (1979). Self-determination and the concept of sovereignty. In Economic Development in American Indian Reservations (pp. 22-28). Albuquerque: University of New Mexico Native American Studies Center.

Elman, C., Kapiszewski, D., \& Vinuela, L. (2010). Qualitative data archiving: rewards and challenges. PS: Political Science \& Politics, 43(1), 23-27.

Harmon, A. (April 21, 2010). Indian tribe wins fight to limit research of its DNA. New York Times. Retrieved from https://www.nytimes.com/2010/04/22/us/22dna.html.

Heaton, J. (2004). Reworking Qualitative Data. Sage.

Hunt, E.P., \& Nabokov, P. (eds.). (2015). The Origin Myth of Acoma Pueblo. New York, NY: Penguin Classics.

Hurley, D.A., Kostelecky, S.R., \& Aguilar, P. (2017). Whose knowledge? Representing indigenous realities in library and archival collections. Collection Management, 42(34), 124-129. doi:10.1080/01462679.2017.1392805.

Irwin, S. (2013). Qualitative secondary data analysis: ethics, epistemology and context. Progress in Development Studies, 13(4), 295-306.

Lomawaima, K.T. (2000). Tribal sovereigns: reframing research in American Indian education. Harvard Educational Review, 70(1 SRC—GoogleScholar), 1-23.

Macaulay, A.C., Delormier, T., McComber, A.M., Cross, E.J., Potvin, L.P., Paradis, G., Kirby, R.L., Saad-Haddad, C., \& Desrosiers, S. (1998). Participatory research with native community of Kahnawake creates innovative code of research ethics. Canadian Journal of Public Health, 89, 105-108.

Matheson, D. (2002). Tribal Sovereignty: preserving our way of life. Arizona State Law Journal, 34, 15.

Mills, K.A. (2017). What are the threats and potentials of big data for qualitative research? Qualitative Research. doi:10.1177/1468794117743465.

Nason, J.D. (1996). Tribal models for controlling research. Tribal College, 7(2 SRCGoogleScholar), 17.

National Commission for the Protection of Human Subjects of Biomedical and Behavioral Research. (1979).The Belmont report: Ethical principles and guidelines for the protection of human subjects of research. Retrieved from https://www.hhs.gov/ohrp/ regulations-and-policy/belmont-report/read-the-belmont-report/index.html.

Navajo Nation. (2005). About NHHRRB. Navajo Nation Human Research Review Board, Navajo Nation Division of Health. Retrieved from http://www.nnhrrb.navajo-nsn.gov/ aboutNNHRRB.html. 
Navajo Nation. (2019). Cultural Resources Compliance Section. Navajo Nation Heritage and Historic Preservation Department. Retrieved from https://www.hpd.navajo-nsn .gov/.

Navajo Nation. (n.d.). Navajo Nation Human Subjects Review Board Procedural Guidelines for Principal Investigators. Navajo Nation Human Research Review Board, Navajo Nation Division of Health. Retrieved from http://www.nnhrrb.navajo-nsn.gov/ pdf/Procedural\%20Guidelines\%20for\%20PI.pdf.

NCAI Policy Research Center and MSU Center for Native Health Partnerships. (2012). "Walk Softly and Listen Carefully": Building Research Relationships with Tribal Communities. Washington, DC and Bozeman, MT: Authors.

Oregon State University. (2016). Tribal Populations. Office of Research Integrity. Human Research Protection and Institutional Review Board. Retrieved from https: //research.oregonstate.edu/irb/policies-and-guidance-investigators/guidance/tribalpopulations.

Pearson, C.R., Parker, M., Zhou, C., Donald, C., \& Fisher, C.B. (2019). A culturally tailored research ethics training curriculum for American Indian and Alaska native communities: a randomized comparison trial. Critical Public Health, 29(1), 27-39.

Raine, S.C., Kukutai, T., Walter, M., Figueroa-Rodrigues, O.L., Walker, J. et al. (2019). Indigenous data sovereignty. In T. Davies, S. Walker, M. Rubinstein, \& F. Perini (eds.), State of Open Data: Histories and Horizons (pp. 300-319). Cape Town: African Minds. doi:10.5281/zenodo.2677801.

Thomson, D., Bzdel, L., Golden-Biddle, K., Reay, T., \& Estabrooks, C.A. (2005). Central Questions of Anonymization: A Case Study of Secondary Use of Qualitative Data. Paper presented at the Forum Qualitative Sozialforschung/Forum: Qualitative Social Research.

Thornton, R. (1987). American Indian Holocaust and Survival: A Population History Since 1492 (The Civilization of the American Indian Series, Vol. 186). Norman: University of Oklahoma Press.

Trope, J.F., \& Echo-Hawk, W.R. (1992). Native American graves protection and repatriation act: background and legislative history, The Arizona State Law Journal, 24,35 .

Tsosie, R. (2007). Acknowledging the past to heal the future: the role of reparations for native nations. In Reparations Interdisciplinary Inquiries (pp. 43-68). Oxford University Press.

United Nations Declaration on the Rights of Indigenous People. (2007). Retrieved from https://www.un.org/esa/socdev/unpfii/documents/DRIPS_en.pdf.

University of Montana. (n.d.). Collaborating with Indigenous People. Research and Creative Scholarship. Retrieved from http://www.umt.edu/research/compliance/IRB/ Indigenous.php.

University of New Mexico. (2012). Guiding Principles for Engaging in Research with Native Communities. Retrieved from https:/hsc.unm.edu/vision2020/common/docs/ Guiding_Principles_Research_Native_Communities2012.pdf.

University of New Mexico. (n.d.). Guidance on Research with American Indian Communities. Office of the Institutional Review Board. Retrieved from https://irb.unm .edu/sites/default/files/Guidance \%20on\%20Research\%20with\%20AI\%20Commun ities.pdf.

University of Washington. (2018). rETHICS - Research Ethics Training for Health in Indigenous Communities. Express Licensing Program. Retrieved from https://els.com 
otion.uw.edu/express_license_technologies/rethics-research-ethics-training-for-health -in-Indigenous-communities.

U.S. Department of Health \& Human Services. (2017). Part 46-Protection of Human Subjects. Office for Human Research Protections. Retrieved from https://www.hhs.gov/ ohrp/regulations-and-policy/regulations/45-cfr-46/index.html.

U.S. Department of Health \& Human Services. (n.d.). 45 CFR 46 FAQs. Office for Human Research Protections. Retrieved from https://www.hhs.gov/ohrp/regulations-and-poli cy/guidance/faq/45-cfr-46/index.html.

Walter, M. (2018) The voice of Indigenous data, beyond the markers of disadvantage. Griffith Review, 60. Retrieved from https://griffithreview.com/articles/voice-Indigeno us-data-beyond-disadvantage/.

White Mountain Apache Tribe. (1996). Resolution of the White Mountain Apache Tribe of the Fort Apache Indian Reservation, Resolution No. 10-96-238. Retrieved from http: //www.wmat.nsn.us/Legal_Scans/Resolutions/1996/10-96-238.\%20Inter-Apache\%20 Policy.pdf.

Wilkins, D.E., \& Stark, H.K. (2017). American Indian Politics and the American Political System. Rowman \& Littlefield. 